\title{
8
}

\section{im

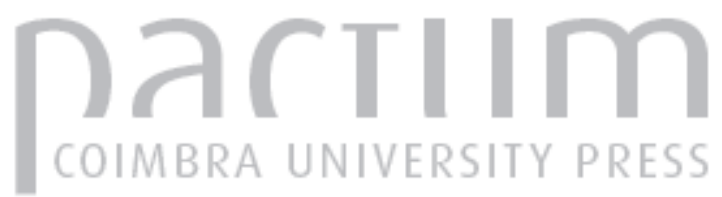

\section{Estratégias de Sobrevivência de Portais, Coletivos e Agências de Conteúdo em Ambiente de Crise}

Autor(es): $\quad$ Seibt, Taís; Lückman, Ana Paula; Amorim, Francisco

Publicado por: Imprensa da Universidade de Coimbra

URL persistente:

URI:http://hdl.handle.net/10316.2/43198

DOI:

DOI:https://doi.org/10.14195/2183-6019_5_1

Accessed : $\quad$ 26-Apr-2023 15:35:25

A navegação consulta e descarregamento dos títulos inseridos nas Bibliotecas Digitais UC Digitalis, UC Pombalina e UC Impactum, pressupõem a aceitação plena e sem reservas dos Termos e Condições de Uso destas Bibliotecas Digitais, disponíveis em https://digitalis.uc.pt/pt-pt/termos.

Conforme exposto nos referidos Termos e Condições de Uso, o descarregamento de títulos de acesso restrito requer uma licença válida de autorização devendo o utilizador aceder ao(s) documento(s) a partir de um endereço de IP da instituição detentora da supramencionada licença.

Ao utilizador é apenas permitido o descarregamento para uso pessoal, pelo que o emprego do(s) título(s) descarregado(s) para outro fim, designadamente comercial, carece de autorização do respetivo autor ou editor da obra.

Na medida em que todas as obras da UC Digitalis se encontram protegidas pelo Código do Direito de Autor e Direitos Conexos e demais legislação aplicável, toda a cópia, parcial ou total, deste documento, nos casos em que é legalmente admitida, deverá conter ou fazer-se acompanhar por este aviso.

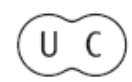


revista de comunicação,

jornalismo e espaço público

\section{5}

Periodicidade

Semestral

Imprensa da Universidade de Coimbra

Coimbra University Press

\section{mediapolis}

crises e os processos comunicativos

crisis and communicative process

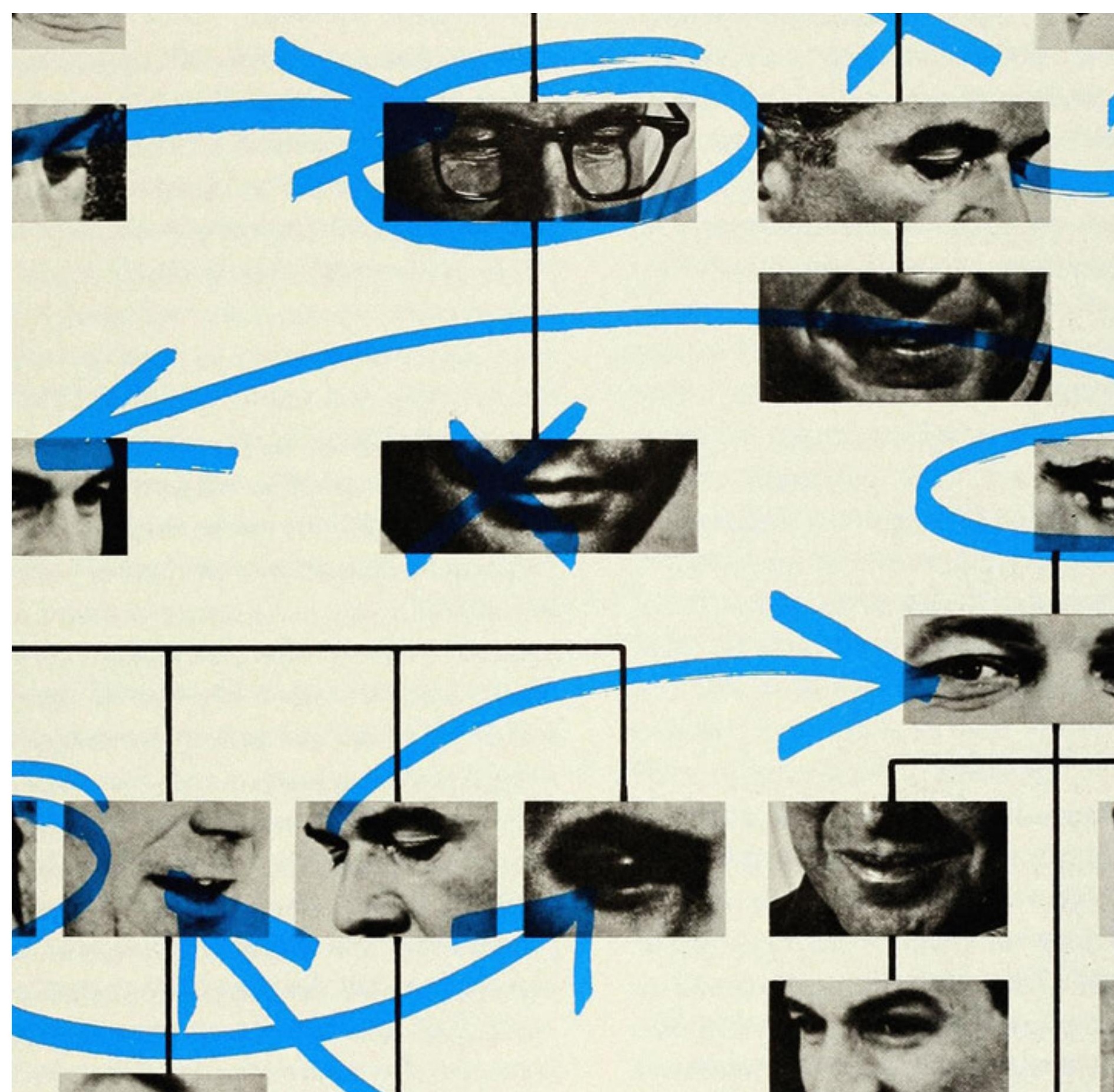




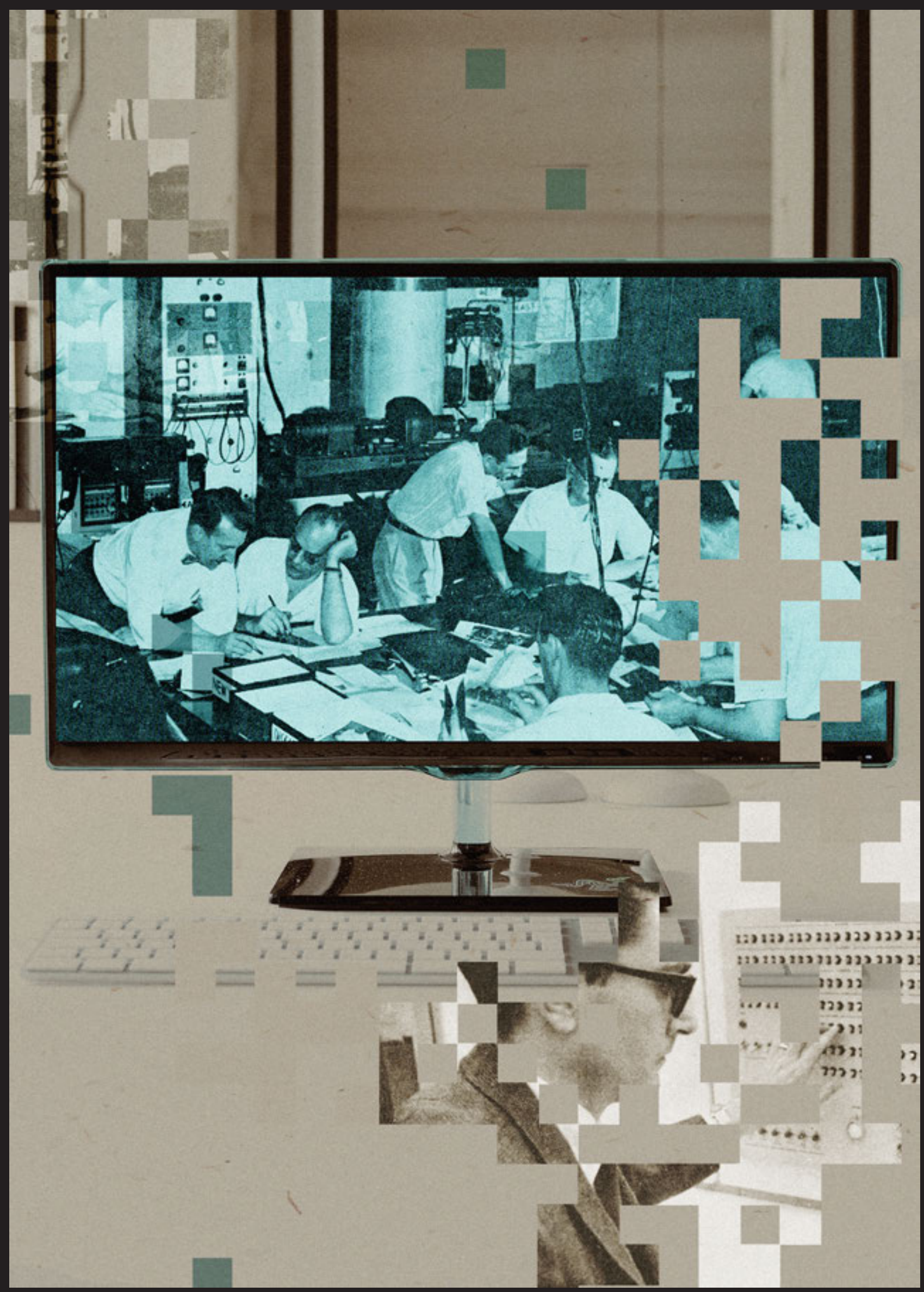




\section{Taís Seibt}

\section{Estratégias de Sobrevivência de Portais, Coletivos \\ e Agências de Conteúdo em Ambiente de Crise ${ }^{l}$}

Universidade Federal do Rio Grande do Sul

Seibt.tais@gmail.com

Ana Paula Lückman

Universidade Federal do Rio Grande do Sul

Ana.luckman@gmail.com

Francisco Amorim

Universidade Federal do Rio Grande do Sul

Chicoreporter@gmail.com

Strategies for the Survival of Internet Portals, Collectives Movements and Content Agencies in Crisis Environments

Resumo:

$\mathrm{O}$ artigo promove uma discussão acerca das transformações no exercício do jornalismo profissional no século XXI, sob a perspectiva da passagem do modelo industrial para o pós-industrial, da crise que se manifesta na e pela transição entre esses modelos e da potencial mudança do paradigma jornalístico que resulta desse processo. Tais proposições são tensionadas com casos empíricos de iniciativas jornalísticas nativas digitais com sede em São Paulo, a fim de apontar, a partir das estratégias de sobrevivência percebidas, tendências para a prática jornalística no novo contexto.

Palavras-chave: jornalismo; jornalismo pós-industrial; jornalismo digital; crise; capitalismo.
Abstract:

This paper discusses the transformations in professional journalism practices in the 21th century, under the perspective of the progression from the industrial model to the post-industrial model, of the crisis drawn in and because of this transition and of the potential change of the journalistic paradigm that results from this process. These proposals are articulated with empiric cases of local digital journalism projects based in São Paulo and their survival strategies, in order to point trends to the journalism practices in this new context.

Keywords: journalism; post-industrial journalism; digital journalism; crisis; capitalism.
1 Uma versão preliminar deste artigo foi apresentada no $14^{\circ}$ Encontro Nacional de Pesquisadores em Jornalismo, na Universidade do Sul de Santa Catarina (Unisul), em Palhoça/SC, de 9 a 11 de novembro de 2016, sob o título "Portais, coletivos e agências de conteúdo: apontamentos sobre as [novas] estratégias de sobrevivência do jornalismo alternativo em São Paulo". 


\section{Introdução}

A indústria jornalística passa por atribulações no cenário comunicacional contemporâneo. Desde o fim do século passado, com o avanço dos sistemas de conexão digital e apropriação crescente de dispositivos de acesso à internet ao redor do mundo, empresas jornalísticas consolidadas têm sido desafiadas a adaptar suas práticas. Concomitantemente, e com ajuda da rede, uma série de mobilizações sociais tomou conta de diferentes países, colocando em xeque a credibilidade de reconhecidos veículos de comunicação. Para completar, o colapso do mercado financeiro atravessa fronteiras, multiplicando os desafios para que o jornalismo se mantenha como um negócio lucrativo nas primeiras décadas do século XXI.

No contexto brasileiro, alguns reflexos perceptíveis desse fenômeno podem ser observados tanto pelos sucessivos enxugamentos em redações de grandes jornais quanto pelo surgimento de novos modelos de atuação jornalística que buscam protagonismo na rede diante de um cenário de contestação da mídia hegemônica. Tais iniciativas nascem tendo a crise como propulsora, mas não passam imunes aos seus efeitos. Muitos projetos nativos digitais ainda não encontraram estratégias de sobrevivência que possam garantir uma estruturação sustentável, como detalharemos neste artigo.

Nosso objetivo é contribuir para a compreensão desse processo em que novos atores ingressam no cenário de produção jornalística. Para tanto, percorreremos o caminho de consolidação da indústria jornalística no século XX e buscaremos problematizar os desafios impostos a esse modelo de atuação no século XXI. A partir de um levantamento empírico focado em iniciativas nativas digitais instaladas em São Paulo, esperamos contribuir para a compreensão de suas estratégias de estruturação, bem como identificar tendências para a prática jornalística no cenário de crise que se desenha.

\section{O jornalismo} no século XX

Ao longo do século XX, o jornalismo se consolidou no âmbito de empresas capitalistas. Foi nesses espaços que se institucionalizaram práticas que ditaram o modelo de jornalismo na sociedade moderna. A origem desse jornalismo informativo remete à chamada "revolução da penny press" (Schudson, 2010: 25), nos anos 1930, quando jornais populares dos Estados Unidos como The New York Sun (1833) e The New York Herald (1835) inauguraram a venda avulsa e ampliaram rapidamente suas tiragens em relação aos concorrentes, que tinham circulação restrita a uma pequena elite que podia pagar por uma assinatura. A investida fez aumentar também o leque de anunciantes e o escopo editorial, não considerando apenas o comércio ou a política, mas a vida social (Schudson, 2010).

Nesse contexto, os jornais passam a funcionar como empresas, produzindo conteúdos cada vez mais diversificados a públicos igualmente variados. Passam a ser meios de comunicação de massa. Há razões culturais, históricas, sociológicas, políticas e econômicas para que o jornalismo, nesses moldes, tenha surgido nos Estados Unidos, apesar de os primeiros periódicos terem circulado na Europa já no século XVI. Havia uma classe média economicamente ativa e alfabetizada em ascensão na sociedade 
estadunidense, graças à política do presidente democrata Andrew Jackson, que buscava representar os anseios do homem comum. Avanços tecnológicos, decorrentes da industrialização estimulada desde o período colonial, permitiram a introdução de impressoras mais rápidas, a ampliação das linhas de trem aumentou o alcance geográfico das publicações e a invenção do telégrafo possibilitou o envio de informações com agilidade jamais imaginada à época.

A partir da segunda metade do século XIX, mais pessoas passam a ter o jornalismo como ocupação principal, os jornais começam a manter correspondentes e até mesmo setoristas para colher notícias em locais ou instituições estratégicas, num movimento que pode ser considerado o embrião para a profissionalização jornalística. No início do século XX, começam a se formar verdadeiros conglomerados de comunicação, a indústria publicitária e de relações públicas ganha força e a atuação em meios de comunicação de massa passa a ser o modelo da atividade jornalística. É esse o jornalismo que chamamos de "tradicional".

O processo de organização da imprensa brasileira em empresas privadas ocorre tardiamente em relação aos países desenvolvidos, o que se justificaria pelo fato de a etapa monopolista do capitalismo no Brasil também ser tardia. O capitalismo só se firma como modo de produção hegemônico a partir da década de 1950, especialmente após o golpe militar de 1964, quando o governo militar institui uma política econômica voltada para a industrialização e passa a incentivar a consolidação das indústrias culturais brasileiras. Ainda que sob censura, o mercado de bens culturais para a "integração nacional" cresce, agregando interesses ideológicos do regime militar e mercadológicos dos empresários.

Resulta desse processo o fortalecimento de conglomerados de comunicação, convertendo o jornal em apenas mais um produto da indústria de bens culturais: a notícia vira mercadoria. $\mathrm{O}$ conteúdo jornalístico se sujeita à lógica capitalista dos conglomerados de comunicação de diferentes maneiras, como produção centralizada, fragmentação do trabalho, controle de processos, setores integrados e fixação do número de páginas em relação ao espaço publicitário. Fonseca (2008: 117) salienta:

\begin{abstract}
"A chamada linguagem jornalística, média, mediana, começa a ser levada ao extremo da simplificação, a ponto de retirar das notícias - cada vez mais breves, mais curtas - qualquer possibilidade de contextualização".
\end{abstract}

\section{Mutações no jornalismo}

Nos primeiros anos do século XXI, o capitalismo entra em um regime de acumulação flexível, pós-fordista, o qual potencializa a conformação das notícias às necessidades do mercado, delineia-se uma nova concepção de jornalismo, “(...) menos relacionada à notícia e mais próxima à informação, prestação de serviço e entretenimento" (Fonseca, 2008: 265). Muda igualmente o perfil do jornalista, que precisa dominar todas as etapas de produção e estar apto a atuar em todos os tipos de mídia. Pesquisadores da Universidade Columbia tomam tais transformações sob a perspectiva de um "jornalismo pós-industrial", na qual “(...) instituições atuais irão perder receita e participação de mercado e que, se quiserem manter ou mesmo aumentar sua relevância, terão 
de explorar novos métodos de trabalho e processos viabilizados pelas mídias digitais" (Anderson et al., 2013: 38).

Os pesquisadores partem da convicção inicial de que o jornalismo é essencial e que é o hard news (notícia de interesse público) que distingue o jornalismo de outros conteúdos que proliferam na rede. Concepção semelhante à que norteia a pesquisa de Virgínia Fonseca, para quem o jornalismo “(...) define-se pelo conceito de notícia, isto é, informação com pré-requisitos jornalísticos, formulado conforme a tradição americana, que se distingue de opinião e de entretenimento" (Fonseca, 2008: 185). Em ambos, a percepção é de que esta concepção de jornalismo encontra-se em declínio no contexto do jornalismo pós-fordista - ou pós-industrial -, o que pode significar o declínio do próprio jornalismo como o conhecemos.

Diferentemente da criação do rádio ou da televisão, em que novos atores foram introduzidos no sistema de mídia, “(...) a internet não trouxe um novo ator para o ecossistema jornalístico. Trouxe um novo ecossistema" (Anderson et al., 2013: 73). Num ambiente em que a comunicação se dá em fluxos multidirecionais, o receptor não é passivo, ele produz, publica, altera e critica o conteúdo na rede. Estratégias de engajamento ganham destaque como elemento de formação de capital social: parece haver mais apelo ao indivíduo que comunica do que à instituição que ele representa, colocando em questão a empresa jornalística como espaço paradigmático para a prática profissional. Tais estratégias de engajamento passam também por interações com o próprio sistema da rede. Tomemos como exemplo o algoritmo do Facebook, que utiliza critérios matemáticos pré-programados para hierarquizar informações conforme hábitos e preferências de cada usuário. Esses elementos frequentemente fazem com que valores-notícia sejam revistos: se a rede social está mobilizada em torno de um assunto, isso é notícia.

Contudo, não caberia ao jornalista apenas reproduzir tal circulação. Os pesquisadores de Columbia defendem que, no jornalismo pós-industrial, o jornalista estaria deslocado a um ponto mais acima na cadeia editorial:

Já não produz observações iniciais, mas exerce uma função cuja ênfase é verificar, interpretar e dar sentido à enxurrada de texto, áudio, fotos e vídeos produzida pelo público (Anderson et al., 2013: 43).

É interessante observar como o movimento contemporâneo da circulação de informações em rede guarda relações com o fenômeno por trás da “revolução da penny press". O mote da imprensa popular estadunidense nos anos 1830 era os assuntos ditos de "interesse humano", a vida social. No ambiente de rede, apartado dos filtros jornalísticos para levar os acontecimentos ao conhecimento público, as informações que circulam têm como foco principal a vida social, aspecto que se potencializa quanto mais o acesso às redes digitais se amplia. $\mathrm{Na}$ mesma medida, há a necessidade de explicar o mundo para uma sociedade que se torna ainda mais complexa.

\section{Jornalismo em crise?}

O cenário descrito por Anderson, Bell e Shirky (2013) sobre o que eles denominam jornalismo pós-industrial apresenta diversos dados empíricos a respeito das mudanças pelas quais o 
jornalismo vem passando nas últimas décadas - mudanças estas que são consideradas por muitos pesquisadores e jornalistas como uma crise tanto do modelo de negócio quanto da atividade em si. No entanto, em geral, o termo crise é tomado com um sentido que se restringe às ideias gerais de incerteza, vacilação ou declínio. A fim de que se estude em maior profundidade essa suposta crise do jornalis$m o$, propomos aqui uma reflexão mais atenta sobre o sentido dessa palavra, para além do senso comum.

O sociólogo francês Edgar Morin propõe que as ciências sociais problematizem a palavra crise a partir da retomada de seu sentido etimológico: originário do grego krisis, o termo significa decisão e, no sentido moderno, incorpora a ideia de incerteza. Isso não significa, para o autor, que tenha ocorrido uma mudança de significado, mas sim a passagem de um sentido simples para um sentido complexo, que denota uma permanente inter-relação entre a decisão e a incerteza. Uma crise necessariamente põe em movimento forças de transformação e suscita a procura de soluções. Ao "pôr em crise a palavra "crise",
Morin propõe que se faça dela um "conceito cientificamente utilizável e epistemologicamente controlável" (Morin, 1984: 115).

Morin (1972: 187) define crise como "complexe d'événements traumatiques affectant le système"1. Entre os elementos centrais de uma situação de crise, destacam-se a paralisia, parcial ou não, no funcionamento de um elemento do sistema; a transformação de diferenças em oposições; o desenvolvimento rápido de novas tendências; o acionamento de estratégias de sobrevivência, que tendam a salvaguardar a integridade do sistema, além de buscas por soluções novas; a relação dialógica entre todos esses elementos. Dessa dialógica pode tanto ocorrer a regressão a um estado anterior e menos complexo, quanto o restabelecimento do status quo. O movimento dialógico dos elementos da crise pode ainda, segundo o autor, levar à inovação, ou seja, ao surgimento de qualidades, complexidades e propriedades novas (Morin, 1972; 2016). Dessa forma, as crises

1 "Complexo de acontecimentos traumáticos que afetam o sistema”, em tradução livre. não são necessariamente evolutivas, pois podem solucionar-se no regresso ao estado anterior; mas são potencialmente evolutivas, na medida em que é próprio dos sistemas em crise o desencadeamento da busca de soluções novas, práticas e criativas. As crises regressivas, ou seja, aquelas que são resolvidas com o retorno a um estado anterior, fazem com que o sistema perca complexidade. Do mesmo modo, as crises progressivas permitem que o sistema adquira qualidades e propriedades novas, isto é, uma maior complexidade (Morin, 1972; 1984; 2016).

\section{O jornalismo nativo digital}

No contexto atual, entendemos que as iniciativas de jornalismo dito "alternativo" ou "independente" que vêm surgindo no Brasil podem revelar aspetos que indiquem uma reação do campo profissional à crise em curso no início do século XXI. Para além de conotações ideológicas implicadas na utilização dos termos acima destacados entre aspas e que estão presentes na apresentação de muitos projetos aqui estudados, o que nos 
interessa é que estas são iniciativas jornalísticas nativas digitais, ou seja, projetos que nasceram em ambiente digital e sem correspondente na imprensa convencional.

No dossiê de Columbia sobre jornalismo pós-industrial, os pesquisadores apontam que a produção de notícias até hoje se alicerçou na combinação de quatro variáveis: capacidade de influência na sociedade (uma instituição fala em pé de igualdade com outras), capital simbólico (os jornalistas sustentaram por muito tempo o título de "guardiões da democracia" ou de "quarto poder"), continuidade (não só a longevidade das empresas, mas a cobertura diária dos acontecimentos) e margem de capacidade (variedade de assuntos cobertos diariamente). Nesse esquema, as mesmas instituições davam conta de produzir dois tipos de informação relevantes: informações sobre acontecimentos públicos e informações especializadas para exercer impacto sobre outras instituições.

Anderson, Bell e Shirky (2013: 57) supõem que o primeiro tipo de informação seja mais facilmente suprido pela comunidade conectada, enquanto o segundo dependeria de uma estrutura institucional. Fazendo projeções, eles apontam características das novas instituições: seriam empresas menores, com novas fontes de financiamento, funcionariam em rede e colocariam em prática novas formas de verificação de informação, adaptadas à internet. Redes colaborativas, como Twitter e Facebook, se solidificariam como fontes de informações sobre fatos ocorridos no último minuto e o papel dos jornalistas seria o de checar e, principalmente, interpretar os acontecimentos. Os mesmos autores apontam que grande parte da questão da institucionalização dessas novatas está ligada à gestão de receitas e despesas, ou seja, o modelo de negócio.

O documento de Columbia sobre jornalismo pós-industrial se propõe inspirar pesquisas que busquem entender como novos esquemas de atuação jornalística se estruturam e que lições e estratégias de cobertura se pode tirar desse processo. Neste artigo, pretendemos tecer algumas observações iniciais com base em iniciativas nativas digitais no jornalismo no Brasil. Para tanto, tomamos a base de dados da Agência Pública², que publicou, em março de 2016, o "Mapa do Jornalismo Independente"3. Segundo a descrição da própria agência, as iniciativas foram catalogadas a partir dos seguintes critérios: organizações que produzem primordialmente conteúdo jornalístico; organizações que nasceram na rede; projetos coletivos, que não se resumem a blogs; sites não ligados a grandes grupos de mídia, políticos, organizações ou empresas. Após um levantamento inicial, com cerca de 100 nomes, foram enviados questionários para confirmar o alinhamento aos critérios.

Como o intuito deste artigo é apresentar inferências iniciais que permitam identificar estratégias de estruturação de novas iniciativas jornalísticas e apontar tendências para o exercício do jornalismo no século XXI, decidimos restringir o corpus a iniciativas com sede em São Paulo, levando em conta que este é o principal

2 A Agência Pública é uma agência brasileira de reportagem e jornalismo investigativo sem fins lucrativos, fundada em 2011. Mais em $<$ http://apublica.org/>

3 Disponível em: <http://apublica.org/mapa-do-jornalismo/ > 
polo econômico do país, onde também se concentram as maiores empresas jornalísticas. Assim, chegamos a um recorte com 35 iniciativas de jornalismo nativas digitais, as quais foram categorizadas segundo padrões estabelecidos conforme nosso interesse de análise.

\section{Percurso Metodológico}

Para a investigação do fenômeno recente, partimos de um modelo explicativo baseado nos métodos quantitativos de natureza descritiva. Nesse sentido, exporemos a seguir as etapas do estudo realizado em 2016 sobre relação entre modelo de negócio e conteúdo editorial de novos empreendimentos jornalísticos, considerados como alternativos, em relação aos veículos de comunicação de massa tradicionais.

\subsection{Definição do objeto empírico}

Para compreender a crise a partir das novas iniciativas jornalísticas surgidas desde o final dos anos 1990, nosso estudo se debruçou sobre
As iniciativas

de Jornalismo

"alternativo" ou

"independente"

que vêm surgindo

no Brasil podem

revelar uma reação

à crise atual projetos criados em São Paulo, estado de maior população e com maior arrecadação tributária do Brasil, onde estão instalados os principais veículos de mídia de massa e os dois principais jornais do país. A escolha recaiu, portanto, sobre a importância estratégica do estado no mercado de comunicação brasileiro.

Tendo São Paulo como lócus da pesquisa, o corpus do estudo passou a ser, por consequência, os empreendimentos surgidos nos últimos anos nesse Estado, que se caracterizariam como alternativa ao jornalismo convencional.

\subsection{Amostra ou universo?}

Delineado o objeto empírico, a próxima informação importante é a de que nos debruçamos sobre o universo de empreendimentos de jornalismo considerados alternativos no cenário paulista listado por uma reconhecida agência de conteúdo e não sobre uma amostra de natureza probabilística. Apesar de garantir maior validade interna, a estratégia não está comprometida com a validade externa. Em outras palavras, as inferências possíveis, do ponto de vista 
estatístico descritivo, estão restritas à realidade de São Paulo dentro do rol de empreendimentos contidos na lista.

\subsection{Dados e unidade de análise, definido o corpus}

Tendo empreendimentos jornalísticos como nossa unidade de análise, a pesquisa utilizou dados coletados sobre as relações entre estratégias de financiamento, segmentos de atuação, abrangência de atuação e natureza dos 35 projetos sediados em São Paulo incluídos na lista da Agência Pública, reconhecida nacionalmente por sua produção jornalística alternativa. Assumimos, portanto, as perdas decorrentes do emprego de uma lista não produzida pelos pesquisadores, mas ressaltamos que a intenção desta estratégia é exatamente compreender também, em alguma medida, como os próprios produtores de conteúdo alternativo - ou pretensamente alternativo - percebem seu mercado.

\subsection{Estratégia de} investigação e definição de variáveis

Em busca de padrões e regularidades que apontem características deste fenômeno social recente, optamos pela estatística descritiva, chegando ao número de seis variáveis categóricas, de valor qualitativo, sobre a existência de financiamento ( de financiamento (tradicional ou alternativa, sendo a primeira formada por assinaturas e publicidade e a segunda por doações, incluindo crowdfunding, atividades correlatas, como realização de cursos, produção de conteúdo de marca, entre outras formas novas de custeio da produção jornalística), natureza (portal, agência, associação civil e coletivo), abrangência (local, nacional ou internacional), data de fundação (até 2009 e a partir de 2010) e segmento (geral, cultura/educação, direitos humanos e economia).

\subsection{Coleta dos dados e técnicas empregadas}

A partir da lista de empreendimentos, as informações foram coletadas entre abril e julho de 2016 nos sites de cada um dos projetos, não sendo realizadas entrevistas para captação de dados complementares. $\mathrm{O}$ artifício teve como objetivo capturar, em alguma medida, o que os projetos tornam público sobre si e o que, eventualmente, omitem sobre cada uma das categorias elegidas pelos pesquisadores.

Os dados sobre a natureza editorial dos projetos foram tomados a partir da análise de conteúdo jornalístico apresentado nos portais e da disposição dos mesmos ao longo do site por meio de seções, subseções e cartolas. Já as informações sobre a manutenção financeira do projeto e sua formação societária, entre outras características administrativas do projeto, foram reunidas tanto a partir da análise de seções do tipo "Quem Somos”, como na verificação da existência de banners de anunciantes, financiadores públicos ou apoiadores.

A etapa seguinte foi a de análise estatística de médias e frequências decorrentes dos cruzamentos entre variáveis relativas ao financiamento, linha editorial e natureza dos empreendimentos. Os primeiros achados do estudo são apresentados nas próximas páginas.

\section{Análise dos dados}

A primeira constatação é que o modelo de negócio preferido neste universo é o de portal de notícias, 
Quadro 1 - Cruzamento entre as categorias natureza e abrangência das iniciativas

Quadro 2 - Cruzamento entre as categorias natureza e financiamento das iniciativas

concentrando mais de $60 \%$ dos empreendimentos, sendo que boa parte deles (45,7\% dos 35) tem ambições nacionais. Dessa forma, os novos projetos parecem inovar pouco na estratégia de estruturação de suas linhas editoriais e produção de conteúdo. Os coletivos, vistos como alternativa mais moderna, representam apenas 17,1\% do total de empreendimentos, como se pode constatar a partir do Quadro 1.

Assim como o modelo de negócio parece não diferir das iniciativas de grupos jornalísticos maiores para fugir da crise, os projetos nativos digitais ainda não descobriram como vencê-la. Como se percebe no Quadro 2, cerca de 1/3 ainda não tem financiamento. Entre os que asseguram ter financiamento, $40 \%$ repetem a fórmula do portal, a mesma dos grandes grupos

\begin{tabular}{|c|c|c|c|c|c|c|}
\hline & \multicolumn{3}{|c|}{ Abrangência } & \multirow[b]{2}{*}{ Total } \\
\hline & & & Local & Nacional & Internacional & \\
\hline \multirow[t]{10}{*}{ Natureza } & \multirow[t]{2}{*}{ Portal } & Contagem & 1 & 16 & 5 & 22 \\
\hline & & $\%$ do Total & $2,9 \%$ & $45,7 \%$ & $14,3 \%$ & $62,9 \%$ \\
\hline & \multirow[t]{2}{*}{ Agência } & Contagem & 2 & 3 & 0 & 5 \\
\hline & & $\%$ do Total & $5,7 \%$ & $8,6 \%$ & $0 \%$ & $14,3 \%$ \\
\hline & \multirow[t]{2}{*}{ Associação civil } & Contagem & 0 & 1 & 0 & 1 \\
\hline & & $\%$ do Total & $0 \%$ & $2,9 \%$ & $0 \%$ & $2,9 \%$ \\
\hline & \multirow[t]{2}{*}{ Coletivo } & Contagem & 3 & 3 & 0 & 6 \\
\hline & & $\%$ do Total & $8,6 \%$ & $8,6 \%$ & $0 \%$ & $17,1 \%$ \\
\hline & \multirow[t]{2}{*}{ Não informado } & Contagem & 0 & 1 & 0 & 1 \\
\hline & & $\%$ do Total & $0 \%$ & $2,9 \%$ & $0 \%$ & $2,9 \%$ \\
\hline & \multirow[t]{2}{*}{ Total } & Contagem & 6 & 24 & 5 & 35 \\
\hline & & $\%$ do Total & $17,1 \%$ & $68,6 \%$ & $14,3 \%$ & $100,0 \%$ \\
\hline
\end{tabular}

\begin{tabular}{|c|c|c|c|c|c|}
\hline & & & \multicolumn{2}{|c|}{ Financiamento } & \multirow[b]{2}{*}{ Total } \\
\hline & & & Sim & Não & \\
\hline \multirow[t]{6}{*}{ Natureza } & Portal & $\begin{array}{l}\text { Contagem } \\
\% \text { do Total }\end{array}$ & $\begin{array}{l}14 \\
40,0 \%\end{array}$ & $\begin{array}{l}8 \\
22,9 \%\end{array}$ & $\begin{array}{l}22 \\
62,9 \%\end{array}$ \\
\hline & Agência & $\begin{array}{l}\text { Contagem } \\
\% \text { do Total }\end{array}$ & $\begin{array}{l}4 \\
11,4 \%\end{array}$ & $\begin{array}{l}1 \\
2,9 \% \\
\end{array}$ & $\begin{array}{l}5 \\
14,3 \% \\
\end{array}$ \\
\hline & Associação civil & $\begin{array}{l}\text { Contagem } \\
\% \text { do Total }\end{array}$ & $\begin{array}{l}1 \\
2,9 \% \\
\end{array}$ & $\begin{array}{l}0 \\
0 \% \\
\end{array}$ & $\begin{array}{l}1 \\
2,9 \% \\
\end{array}$ \\
\hline & Coletivo & $\begin{array}{l}\text { Contagem } \\
\% \text { do Total }\end{array}$ & \begin{tabular}{|l}
5 \\
$14,3 \%$ \\
\end{tabular} & $\begin{array}{l}1 \\
2,9 \% \\
\end{array}$ & $\begin{array}{l}6 \\
17,1 \%\end{array}$ \\
\hline & Não informado & $\begin{array}{l}\text { Contagem } \\
\% \text { do Total }\end{array}$ & $\begin{array}{l}1 \\
2,9 \% \\
\end{array}$ & 0 & $\begin{array}{l}1 \\
2,9 \% \\
\end{array}$ \\
\hline & Total & $\begin{array}{l}\text { Contagem } \\
\% \text { do Total }\end{array}$ & $\begin{array}{l}25 \\
71,4 \%\end{array}$ & $\begin{array}{l}10 \\
28,6 \%\end{array}$ & $\begin{array}{l}35 \\
100,0 \%\end{array}$ \\
\hline
\end{tabular}

\section{Independentemente}

\section{do modelo de}

negócio, a aposta é

\section{em uma estratégia}

tradicional de

fazer jornalismo midiáticos. A adoção de uma estratégia comum é algo que desperta a atenção quando miramos o fato de que $62,9 \%$ dos empreendimentos foram criados a partir de 2010, depois do início dos enxugamentos nas grandes redações, que adotaram os portais como modelos de editorial para ingressar e sobreviver no mundo digital.

Outra consideração importante, possível a partir do cruzamento estatístico descritivo destes 35 empreendimentos, pode ser observada no Quadro 3. Apesar de apostarem no modelo editorial consagrado, os empreendimentos buscam formas alternativas de se sustentar. Mais de metade assume uma estratégia que inclui formas não tradicionais de financiamento, como doações e realização de atividades não ligadas diretamente à atividade-fim do 
Quadro 3 - Cruzamento entre as categorias natureza e estratégias de financiamento das iniciativas

Quadro 4 - Cruzamento entre as categorias natureza e segmento das iniciativas

projeto. Cerca de 1/3 não informa ou não tem estratégia de financiamento, o que levanta questionamentos sobre sua capacidade de se concretizar como negócio jornalístico.

Quando se busca compreender a relação entre modelo de produção/ distribuição de notícias e a linha editorial/temática eleita, a partir do Quadro 4 é possível perceber que a linha Geral é a predominante.

Em outras palavras, independentemente do modelo de negócio, a aposta é em uma estratégia tradicional de fazer jornalismo, abordando variados temas, seguindo a tática aberta dos grandes jornais. Uma pequena inflexão pode ser observada entre os coletivos, mas nada que pontue significativamente para mudar a configuração do geral

\begin{tabular}{|c|c|c|c|c|c|c|}
\hline & & & \multicolumn{3}{|c|}{ Estratégia de Financiamento } & \multirow[b]{2}{*}{ Total } \\
\hline & & & Tradicional & Alternativa & Não informado & \\
\hline \multirow[t]{6}{*}{ Natureza } & Portal & $\begin{array}{l}\text { Contagem } \\
\% \text { do Total }\end{array}$ & $\begin{array}{l}4 \\
11,4 \%\end{array}$ & $\begin{array}{l}10 \\
28,6 \%\end{array}$ & $\begin{array}{l}8 \\
22,9 \%\end{array}$ & $\begin{array}{l}22 \\
62,9 \%\end{array}$ \\
\hline & Agência & $\begin{array}{l}\text { Contagem } \\
\% \text { do Total }\end{array}$ & $\begin{array}{l}0 \\
0 \%\end{array}$ & $\begin{array}{l}3 \\
8,6 \%\end{array}$ & $\begin{array}{l}2 \\
5,7 \%\end{array}$ & $\begin{array}{l}5 \\
14,3 \%\end{array}$ \\
\hline & Associação civil & $\begin{array}{l}\text { Contagem } \\
\% \text { do Total }\end{array}$ & $\begin{array}{l}0 \\
0 \%\end{array}$ & $\begin{array}{l}1 \\
2,9 \%\end{array}$ & $\begin{array}{l}0 \\
0 \%\end{array}$ & $\begin{array}{l}1 \\
2,9 \%\end{array}$ \\
\hline & Coletivo & $\begin{array}{l}\text { Contagem } \\
\% \text { do Total }\end{array}$ & \begin{tabular}{|l|}
0 \\
$0 \%$ \\
\end{tabular} & \begin{tabular}{|l|}
5 \\
$14,3 \%$ \\
\end{tabular} & $\begin{array}{l}1 \\
2,9 \% \\
\end{array}$ & $\begin{array}{l}6 \\
17,1 \%\end{array}$ \\
\hline & Não informado & $\begin{array}{l}\text { Contagem } \\
\% \text { do Total }\end{array}$ & $\begin{array}{l}0 \\
0 \% \\
\end{array}$ & $\begin{array}{l}1 \\
2,9 \%\end{array}$ & $\begin{array}{l}0 \\
0 \% \\
\end{array}$ & $\begin{array}{l}1 \\
2,9 \%\end{array}$ \\
\hline & Total & $\begin{array}{l}\text { Contagem } \\
\% \text { do Total }\end{array}$ & $\begin{array}{l}4 \\
11,4 \%\end{array}$ & $\begin{array}{l}20 \\
57,1 \%\end{array}$ & $\begin{array}{l}11 \\
31,4 \%\end{array}$ & \begin{tabular}{|l|}
35 \\
$100,0 \%$ \\
\end{tabular} \\
\hline
\end{tabular}

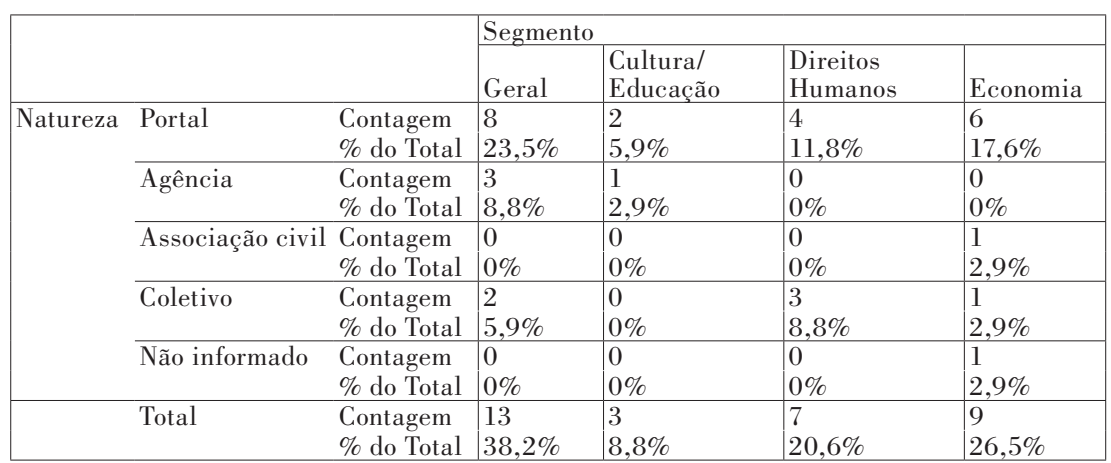

das estratégias discursivas adotadas pelos projetos alternativos, que, mais uma vez, se mostram mais convencionais do que alternativos.

\section{Considerações finais}

Ensaiando tendências para o jornalismo pós-industrial, Anderson, Bell e Shirky (2013) apontam que grande parte da questão da institucionalização de novas formas de se fazer jornalismo está ligada à sustentabilidade financeira. Características que garantiram a consolidação do jornalismo no século XX, como a capacidade de interferir na sociedade a partir da cobertura diária dos acontecimentos em uma variedade de assuntos, somente se firmaram porque a imprensa comercial desenvolveu um modelo de negócio não só sustentável, mas também lucrativo.

Se a virada para a era digital sugere que tal modelo está em crise, por outro lado nossos achados indicam pouca inovação nas fontes de receita e até mesmo na forma de distribuição de conteúdo jornalístico na rede, vide o grande número de portais financiados por meio de anúncios e assinaturas.

A partir da análise estatística descritiva sobre o universo de empreendimentos jornalísticos nativos digitais em São Paulo, pode-se inferir que as estratégias de negócios e as linhas editoriais - em termos de seleção de temas - aproximam projetos alternativos e tradicionais. A incapacidade de financiamento permanece como ponto fraco também entre as propostas fora dos grandes veículos, e nesse aspecto 
destaca-se ainda o alto percentual de portais que buscam alternativas não convencionais de financiamento.

No que diz respeito ao potencial "alternativo" das iniciativas analisadas, pode afirmar-se que a principal diferença entre tais portais e os veículos tradicionais é o suporte digital sem equivalente ao produto principal impresso, como ocorre com os grandes jornais da imprensa de referência. $\mathrm{Pa}$ rece inegável que o jornalismo passa por um período de crise, no sentido moriniano do termo e com todas as implicações desse sentido. As crises têm um potencial evolutivo, como ensina Morin; no entanto, nos casos aqui analisados, a práxis ainda remete mais à manutenção de métodos e procedimentos do que ao desenvolvimento de soluções novas e criativas, que seriam, aí sim, características de uma crise progressiva.

Este artigo leva em conta um levantamento inicial, com recorte restrito, mas suficiente para sinalizar a limitada inovação no que se refere a novos modelos de jornalismo. Certamente mais estudos são necessários, a fim de indicar possibilidades sustentáveis para que novos projetos ultrapassem o status de mídias "alternativas" e possam efetivamente configurar um novo modelo para o exercício do jornalismo na era pós-industrial. Ressaltamos, inclusive, a importância de que sejam desenvolvidos estudos qualitativos sobre essas iniciativas, com foco em discurso, conteúdo e processos de produção jornalística, para que se aprofunde a compreensão do atual momento do jornalismo.

\section{Referências bibliográficas}

Anderson, C.; Bell, E. \& Shirky, C. (2013). Jornalismo pós-industrial: adaptação aos novos tempos. Revista ESPM, 5(2), 30-89.

Fonseca, V. P. S. (2008). Indústria de Notícias: Capitalismo e novas tecnologias no jornalismo contemporâneo. Porto Alegre : Editora da UFRGS.

Morin, E. (1972). L'événement-Sphinx. Communications, 18, 173-192. DOI: 10.3406/comm.1972.1273.

Morin, E. (1984). Sociologia. Mem Martins: Publicações Europa-América. Morin, E. (2016). Pour une Crisologie. Paris: Éditions de L'Herne.

Schudson, M. (2010). Descobrindo a Notícia: Uma história social dos jornais nos Estados Unidos. Petrópolis: Vozes. 